ORIGINAL ARTICLE

Iran J Allergy Asthma Immunol

June 2016; 15(3):174-182.

\title{
Reduced Phagocytic Capacity of Blood Monocyte/Macrophages in Tuberculosis Patients Is Further Reduced by Smoking
}

\author{
Mahshid Aryanpur ${ }^{1}$, Esmaeil Mortaz ${ }^{2,3,4}$, Mohammad Reza Masjedi ${ }^{5}$, Payam Tabarsi ${ }^{6}$, \\ Johan Garssen $^{7}$, Ian M. Adcock ${ }^{4}$, Alireza Mozafarian ${ }^{3}$, Hooman Sharifi ${ }^{1}$ \\ ${ }^{1}$ Tobacco Prevention and Control Research Center, National Research Institute of Tuberculosis and Lung Diseases \\ (NRITLD), Shahid Beheshti University of Medical Sciences, Tehran, Iran \\ ${ }^{2}$ Department of Immunology, National Research Institute of Tuberculosis and Lung Diseases (NRITLD), Shahid Beheshti \\ University of Medical Sciences, Tehran, Iran \\ ${ }^{3}$ Chronic Respiratory Diseases Research Center, National Research Institute of Tuberculosis and Lung Diseases (NRITLD), \\ Shahid Beheshti University of Medical Sciences, Tehran, Iran \\ ${ }^{4}$ Airways Disease Section, National Heart and Lung Institute, Imperial College London, London,UK \\ ${ }^{5}$ Chronic Respiratory Diseases Research Center, National Research Institute of Tuberculosis and Lung Diseases (NRITLD), \\ Shahid Beheshti University of Medical Sciences, Tehran, Iran \\ ${ }^{6}$ Clinical Tuberculosis and Epidemiology Research Center, National Research Institute of Tuberculosis and Lung Diseases \\ (NRITLD), Shahid Beheshti University of Medical Sciences, Tehran, Iran \\ ${ }^{7}$ Division of Pharmacology and Pathophysiology Utrecht Institute for Pharmaceutical Sciences, Faculty of Sciences, Utrecht \\ University, Utrecht, Netherlands
}

Received: 11 October 2015; Received in revised form: 20 January 2016; Accepted: 31 January 2016

\begin{abstract}
Tuberculosis (TB) and tobacco use are two major alarming global health issues posing immense threats to human populations. Mycobacterium tuberculosis (MTB) by activation of macrophages could induce the sequences of cells activation and releases of inflammatory cytokines such as CXCL-8, Il-12 and TNF- $\alpha$ which in turn induces the immune system network. However no information is available on other activity of cells by MTB and smoking. In the current study we aimed to investigate the serum levels TNF- $\alpha$, CXCL- 8 and phagocytosis capacity in tuberculosis patients with and without smoking.

103 subjects entered the study including 61 new diagnosed pulmonary TB patients $(23$ smokers and 38 nonsmokers) and 42 control healthy subjects. The phagocytosis of fluorescein isothiocyanate dextran (FITCdextran) in blood monocytes/macrophages through flowcytometry was assessed. Serum levels of TNF- $\alpha$ and CXCL- 8 were analyzed by ELISA methods.

A lower percentage of cells from TB patients who smoked [50.29\% (43.4-57.2), $p<0.01]$ took up FITCdextran after $2 \mathrm{~h}$ compared to non-smoking TB subjects [71.62\% (69.2-74.1)] and healthy cases [97.45\% (95.999.1). Phagocytic capacity was inversely correlated with cigarette smoking as measured by pack years $(\mathrm{r}=-0.73$, $p<0.001)$. The serum levels of TNF- $\alpha$ and CXCL- 8 were significantly higher in the TB patients who smoked compared to the TB non-smoker group ( $p<0.001, p<0.01$ respectively).

Blood monocytes/macrophages from TB patients have reduced phagocytic capacity which is further reduced in TB patients who smoke. Smoking enhanced serum levels of TNF- $\alpha$ and CXCL- 8 suggesting a greater imbalance between the proinflammatory and anti-inflammatory factors in these patients.
\end{abstract}

Keywords: Chemokine CXCL8; Phagocytosis; Smoker; TNF-alpha; Tuberculosis

Corresponding Author: Esmaeil Mortaz, PhD;

Department of Immunology, National Research Institute of Tuberculosis and Lung Diseases (NRITLD), Shahid Beheshti
University of Medical Sciences, Tehran, Iran. Tel: (+98 21) 2610 9991, Fax: (+98 21) 2610 9484, E-mail: e.mortaz@ imperial.ac.uk 


\section{Attenuation Release of TNF and CXCL-8 in TB and Smoking}

\section{INTRODUCTION}

The association between tobacco smoke and tuberculosis (TB) has been considered recently. Tuberculosis (TB) and tobacco use are two major alarming global health issues posing immense threats to human populations. ${ }^{1}$ Most of the morbidity and mortality from tuberculosis occurs in developing countries, which incidentally, smoking is still the most common problem. ${ }^{2}$

Mycobacterium Tuberculosis (Mtb) is an intracellular pathogen of human mononuclear phagocytes. As with many other bacteria, the interaction of Mtb with innate and adaptive immune mechanisms specifies the infection prognosis. ${ }^{3}$

Mtb has developed mechanisms to evade from immune surveillance at many steps in the host response. $^{4,5}$ Mtb may impair the recognition of phagocytic activity of macrophages and neutrophils in different ways.

It has been proposed that the correlation of $\mathrm{TB}$ and smoking could be due to the inhibitory effect of nicotine on production of TNF- $\alpha$ by the lung macrophages which make the patients susceptible to the development of progressive latent infection to the active form. ${ }^{6}$

Smoking impairs the phagocytic function of alveolar macrophages. ${ }^{7}$ Both smoking and tuberculosis induce apoptosis of macrophages. ${ }^{8,9}$ Cigarette smoke activates macrophages to produce a local inflammatory response, ${ }^{10}$ but nicotine as important component of smoke suppresses the antigen presentation function to develop a specific immune response. ${ }^{11}$ Chronic exposure to cigarette smoke reduces expression of surface proteins related to antigen presentation by macrophages. $^{12,13}$

Macrophage/monocyte is important in the function of the immune system and macrophage-derived cytokines play role in the immune system. ${ }^{14} \mathrm{Mtb}$ infection recruit the Inflammatory cells in the lungs and these infiltrating cells constitute into a construction named granuloma that controls and contains infection. ${ }^{15}$ The formation process of granulomas and its influencing factors are unknown but it seems that the TNF- $\alpha$ plays an important role in this process. ${ }^{15}$ TNF- $\alpha$ produced by the macrophages which activated by endotoxins. $^{16}$ Treatments that modulate TNF- $\alpha$ production are reported to be associated with higher susceptibility of patients to TB disease and may reactivate the latent from of diseases. ${ }^{17,18}$

Interleukin-8 (CXCL8) is found to be chemo attraction and regulation of white blood cell production $^{15}$ which can affect the pathogenesis of intensive infectious diseases such as TB by suppressing the normal immune response to Mtb that can lead to granuloma formation. ${ }^{19}$ Although monocytes and macrophages infected with Mtb are the main sources of CXCL8 production, ${ }^{20}$ but it can also be produced by neutrophils and respiratory epithelial cells as well. ${ }^{21,22}$ It is probable that CXCL8 is responsible for aggregation of neutrophils at infection sites in TB patients, however, it has not been proven yet. ${ }^{23}$

Cigarette smoking is a major risk factor for acute and chronic respiratory tract infections and can be expected to affect human health. ${ }^{24}$ Modulation of macrophage function by tobacco and smoking has been extensively reviewed. ${ }^{25}$ Aqueous phases ${ }^{26}$ of cigarette smoke with more than 5000 compounds exist in blood stream, ${ }^{27-29}$ and those particles could affect on inflammatory cells. ${ }^{30}$ These compound enter to the cells and activate / suppress the activity of macrophage. ${ }^{7,10}$

In fact MTB by activation of macrophages via dectin receptor activate the sequences of cells activation and release of inflammatory cytokines such as CXCL-8, Il-12 and TNF- $\alpha$ release which in turn induces the immune system network. ${ }^{31-33}$ However we don't know how phagocytosis suppression happened in TB and cigarette smoke patients. Only we could speculate that smoking suppress the capacity of cells which induces phagocytosis.

Our study goal was to define smoking effects on the phagocyte capacity of blood monocytes/macrophages and levels of inflammatory mediators such as TNF- $\alpha$ and CXCL- 8 in TB patients.

\section{MATERIALS AND METHODS}

103 subjects including 61 newly diagnosed pulmonary TB patients $(23$ smokers and 38 nonsmokers) and 42 controls healthy cases were studied. Smoker patients had history of $26.4 \pm 16.3$ pack-year smoking. Control and non-smoker TB patients were selected from people with no history of passive smoking.

Samples were selected from both genders, aged 18 years and older. Inclusion criteria were as follows: being diagnosed with active pulmonary TB based on the classification extracted from the WHO treatment 
guidelines $^{34}$ and being classified as a category I patients (new TB cases). Subjects were excluded if they had only extra pulmonary TB (involving CNS, pericardium, adrenal gland etc.), had multi-drug resistant $\mathrm{TB}$ at diagnosis, had HIV/AIDS, were an active IV drug abuser, were classified as category II (relapse, treatment failure, and treatment after default) or category III (chronic TB), fulfilled the eligibility criteria but were not willing to participate in the study or were unable to comprehend the contents of the informed consent form.

\section{Chemicals and Reagents}

Fluorescein isothiocyanate (FITC)-dextran (average molecular mass, $40 \mathrm{kDa}$ ) was purchased from SigmaAldrich (St. Louis, Mo., USA). CXCL-8 (R\&D system,USA),TNF- $\alpha$ (Invitrogen ,USA) ELISA kits, Ficoll- hypaque (Pharmacia, Uppsala, Sweden), FCS (fetal Calf serum, Greiner Bio-One, Germany).

\section{Isolation of Monocytes/Macrophages from Peripheral Blood}

Venous blood was drawn from cases in all groups; healthy volunteers and TB patients and harvested in coagulated tubes containing the $1 / 10$ vol of $3.8 \%$ sodium citrate. Peripheral blood mononuclear cells (PBMC) were prepared by Ficoll-hypaque density gradient isolation by centrifugation of freshly drawn blood. PBMC were seeded for $1 \mathrm{~h}$ in a cell culture flask before non-adherent cells were removed. Adherent cells were considered as a monocyte/macrophage subgroup of PBMC. Thereafter, the cells were washed once with PBS (1X) and suspended in buffer containing $1 \mathrm{ml}$ PBS-1\% Fetal calf serum (FCS). We stained the cells for CD14 marker and then analyzed by flow cytometry (FACS Calibour), which was always in the range of $90 \%-95 \%$. The isolated monocytes were used freshly or frozen at $-130^{\circ} \mathrm{C}$ for later use.

\section{Phagocytosis Assays}

Phagocytosis was assayed by flow cytometry using FITC-dextran. ${ }^{35}$ The removed cells $\left(5 \times 10^{4}\right)$ were suspended in $100 \mu \mathrm{PBS}$ including $1 \%$ bovine serum albumin and incubated together with FITC-dextran $(0.1 \mathrm{mg} / \mathrm{ml})$ at $37^{\circ} \mathrm{C}$ or $4^{\circ} \mathrm{C}$ for $2 \mathrm{hrs}$ as described previously. ${ }^{36}$ Incubation was stopped by mixing with $2 \mathrm{ml}$ ice-cold PBS that include 1\% human serum and $0.02 \%$ sodium azide. The cells were washed three times, with cold PBS and FACS Calibour flow cytometer (FACS Calibour, BD bioscience, USA) was used for analysis. Specific FITC-dextran uptake of each sample was expressed as the total FL1 fluorescence intensity at $37^{\circ} \mathrm{C}$ minus total FL-1 fluorescence intensity at $4^{\circ} \mathrm{C}$. Relative endocytosis activity was calculated using the formula specific FITC-dextran uptake of sample/specific FITC-dextran uptake of control $\times 100 \%$.

\section{Trypan Blue Quenching}

In order to eliminate the effects of membrane adherent FITC-Dextran, phagocytosis was evaluated by comparing the intensity of green fluorescence (FITC) before and after trypan blue quenching of membrane-bound, labeled dextran. For stopping extracellular fluorescence, after exposure to FITCDextran, cells were pelleted by centrifugation $(10,000$ $\mathrm{xg}$ at $4{ }^{\circ} \mathrm{C}$ for $5 \mathrm{~min}$ ) and then resuspended in ice -cold $0.2 \%$ Trypan blue in $1 \mathrm{x}$ PBS $(100 \mu \mathrm{l})$ as described earlier. ${ }^{37}$ Then 10000 cells were analyzed by flow cytometry .

\section{TNF- $\alpha$ and CXCL-8 Measurements}

Drawing venous blood samples was performed between 7:30 and 8:00 $\mathrm{AM}$ in the morning before having breakfast and for the smoker subjects before the first cigarette of the day. Samples were immediately centrifuged 10 minutes at a speed of $1500 \mathrm{rpm}$. Prior to analysis the serum was stored at $-20^{\circ} \mathrm{C}$. The serum levels of TNF- $\alpha$ and CXCL-8 were analyzed by using the mentioned ELISA kits according to manufacture Instruction. ${ }^{38}$ The detection threshold level in both kits was $31.2 \mathrm{pg} / \mathrm{ml}$.

\section{Statistical Analysis}

Results are presented as means \pm standard error of the mean (S.E.M.). SPSS v.18.0 software was used to analyze the data. Since some of the data sets were not normally distributed, group comparisons were performed using non parametric tests and Kruskal Wallis H test.Spearman's rank correlation coefficients were calculated $p<0.05$ was considered significant.

\section{RESULTS}

The important Demographic character of study populations was shown below (Table 1). 
Table 1. Demographic characteristics of smoker and nonsmoker patients with TB and without TB

\begin{tabular}{lcccc}
\hline Variables & Healthy Controls & TB-Non-smokers & TB-Smoker & $p$ value \\
\hline Number of subjects & 42 & 38 & 23 & \\
Age & $53.9 \pm 4.3$ & $54.2 \pm 6.5$ & $53.7 \pm 5.2$ & NS \\
Sex(Male \%) & $30(71 \%)$ & $17(74 \%)$ & $11(73 \%)$ & NS \\
Pack/Years & 0 & 0 & $26.4 \pm 16.3$ & \\
Marriage status (\% single) & $15(35.7 \%)$ & $14(36.8 \%)$ & $8(34.7 \%)$ & NS \\
Job(manual) & $18(42.9 \%)$ & $18(47.4 \%)$ & $12(52.2 \%)$ & $<0.05$ \\
\hline
\end{tabular}

Results presented as Mean \pm SD where appropriate, NS, not significant

\section{Smoker TB Patients Showed Lower Phagocytosis Capacity}

A lower percentage of peripheral blood monocyte/macrophage cells from smoking TB subjects [50.29\% (43.4-57.2)] took up FITC-dextran after $2 \mathrm{~h}$ compared with non-smoking TB patients $[71.62 \%$ (69.2-74.1)] and healthy controls [97.45\% (95.9-99.1)] (Figure 1). Phagocytosis was significantly reduced in non-smoking TB subjects compared to healthy controls (Figure 1). Inhibition of phagocytosis by cytochalasine D $(10 \mathrm{mg} / \mathrm{ml})$ prevented FITC-dextran uptake (data not shown) and cells cultured at $4^{\circ} \mathrm{C}$ showed significant reduced phagocytosis (data not shown).

We further evaluated in smoker's phagocytosis capacity suppression according smoking pack-years, there was an inverse correlation between the suppression of phagocytosis and pack-years ( $\mathrm{r}=-0.73$, $p<0.001)$. There was no significant correlation between suppression of phagocytosis and any demographic factors including age, sex, job, education and marriage status.

\section{TB Smokers Have Higher Serum Levels of Inflammatory Cytokines}

The serum levels of TNF- $\alpha$ and CXCL- 8 were significantly higher in the smoking TB group than in the healthy non-smoking subjects $(p<0.01$; Figures 2 and 3). Serum TNF- $\alpha$ was also higher in smoking TB patients compared to non-smoking TB subjects $(p<0.05$, Figure 2$)$.

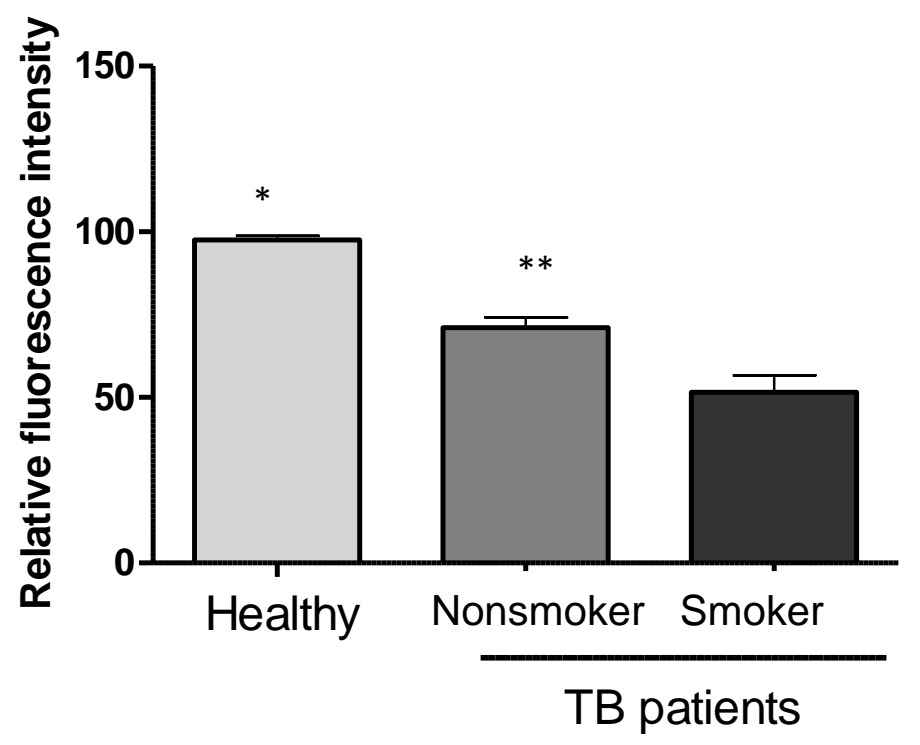

Figure 1. Suppression of phagocytosis in TB and TB+Smoker patients.

Uptake of FITC-dextran by peripheral blood monocytes/macrophages was measured by relative fluorescence intensity after $2 \mathrm{hrs}$ in healthy control subjects and in smoking and non-smoking TB patients. Data are presented as mean \pm S.E.M. of experiments. ${ }^{*} p<0.05$, $* * p<0.01$ versus the study's healthy subjects. 


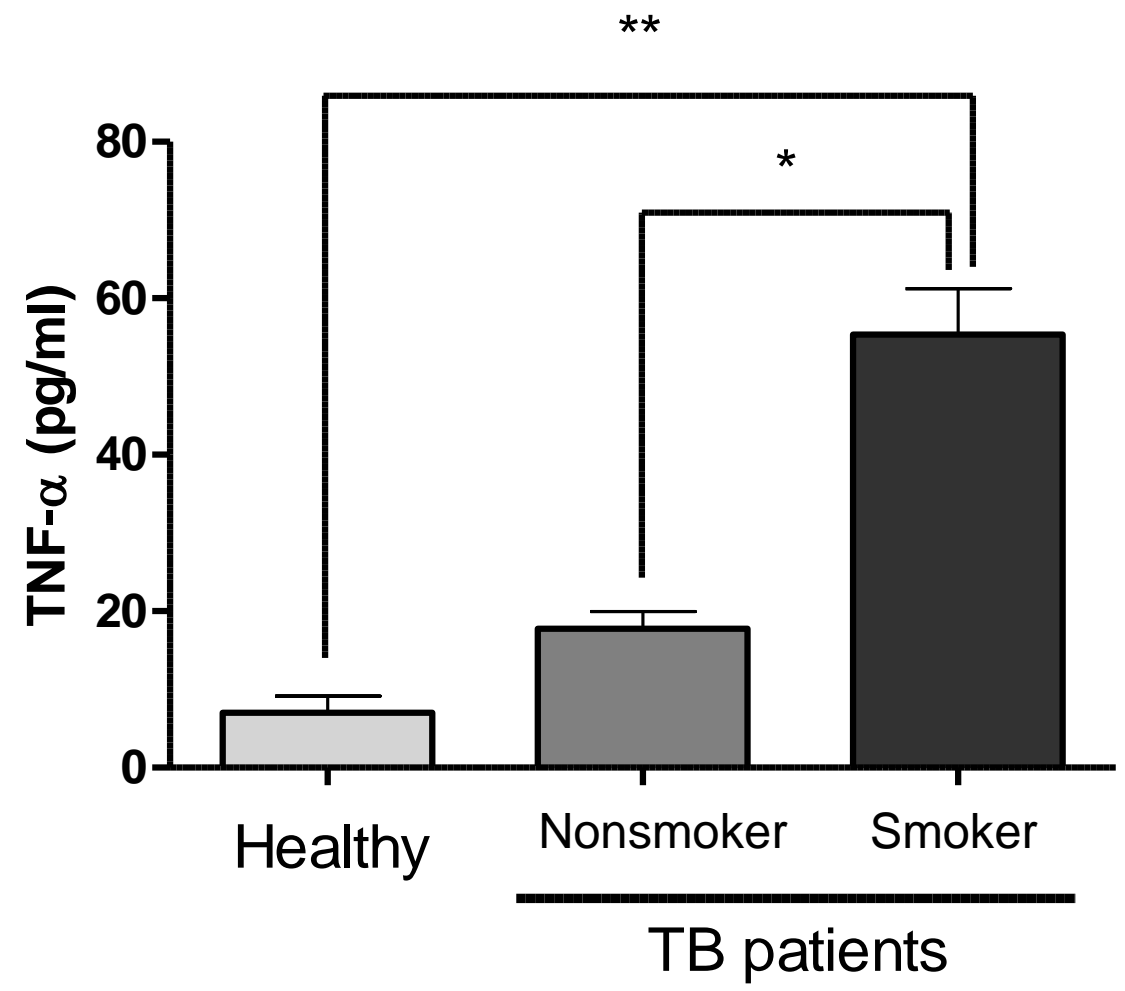

Figure 2. Serum levels of $T N F \alpha$ in healthy controls $(n=42)$ and smoking $(n=23)$ and non-smoking $(n=38)$ TB patients. Data are presented as mean \pm S.E.M. $* p<0.05$, $* * p<0.01$ versus healthy subjects.

There was no correlation between TNF- $\alpha$ levels and pack years or demographic factors between smokers $\mathrm{TB}$ and smokers. In contrast, there was a positive correlation between CXCL-8 increase and pack years in the smoking TB group $(\mathrm{r}=0.58, p<0.05)$.

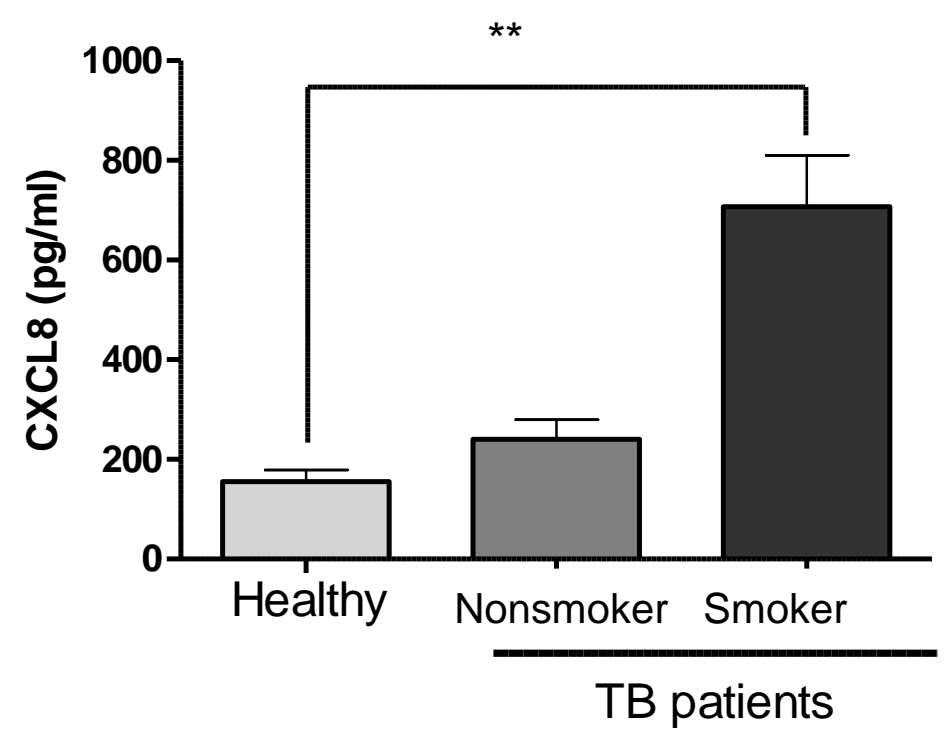

Figure 3. Serum levels of CXCL8 in healthy controls $(n=42)$ and smoking $(n=23)$ and non-smoking (n=38) TB patients. Data are presented as mean \pm S.E.M.** $p<0.01$ versus healthy subjects. 


\section{DISCUSSION}

In the current study blood monocytes/macrophages from TB patients showed reduced phagocytic capacity which is further reduced in TB patients who smoke. Besides, smoking enhanced serum levels of TNF $\alpha$ and CXCL8 in TB patients above that seen in healthy controls. TNF $\alpha$, but not CXCL8, serum levels were also elevated in TB patients who smoked compared to those who were non-smokers.

According to the WHO, more than $30 \%$ of world's population may be infected with Mtb, and in most highburden regions, it ranks after cardiovascular disease, as the second problem. ${ }^{39,40}$ Each year 8.6 million people develop TB disease and 1.3 million die of the disease. ${ }^{41}$ The association between tobacco smoking and tuberculosis has been described recently. ${ }^{42}$ The biological mechanisms that affect smoking risk on TB infection include decrease in ciliary function, alterations in macrophage number and response. ${ }^{33,34}$ Due to suppression effects of tobacco smoking on the immune response, studies of this effect on the macrophages recently much appreciated. ${ }^{44} \mathrm{We}$ have shown that TB patients have a reduced phagocytic capacity compared to healthy subjects and this is further attenuated in TB patients who smoke. Previous studies have revealed a lower phagocytosis of smokers in comparison with non-smokers. ${ }^{45}$

One of the most important roles of macrophages in the lungs of smokers is clearing the particles entered the lungs through tobacco smoking. ${ }^{46}$ In this regard, it is of interest to assess the effects of tobacco smoke on phagocytic capacity of macrophages. Accordingly, macrophages isolated from the lungs of smoke-exposed mice were found to have decreased capacity to bind and internalize yeasts. ${ }^{47}$ The larger phagolysosomes found in lung macrophages of smoker subjects compared to non-smokers indicate that regardless of its influence on phagocytosis, smoking suppresses the breakdown of ingested particles in lysosomes. ${ }^{48}$ These observations suggest that a central feature of TB pathogenesis involves mycobacterial interference with, or evasion of, phagocyte activation pathways which normally lead to the killing of ingested organisms.

This finding is congruent with results of previous studies reporting a significant increase in activation of TNF- $\alpha$ pathway in cigarette smokers. ${ }^{49,50}$ Production of CXCL8 in epithelial cells is also shown to increase through exposure to bacterial endotoxin and TNF- $\alpha .^{51}$
No consensus has been reached on the role of CXCL-8 in pathogenesis of TB. Several studies have shown that multiple growth factors, cytokines and other mediators might be able to interact with bacterial pathogens influencing the release of inflammatory mediators. ${ }^{52,53}$ It has been proposed that cytokine releases could be modulated by smoking. ${ }^{54}$ Our data indicate that CXCL8 could be associated to TB infection in patients who smoke as there was a further increase of serum CXCL8 levels and a direct correlation with cigarette smoking as defined by pack years in these patients. It can be concluded from this observation that a significant exposure of cigarette smoke is necessary for activating inflammatory processes. Other evidences were indicated the serum and BAL fluid's CXCL-8 concentration increase in active TB patients, ${ }^{55,56}$ even in some cases it reached to 8.9 times the normal limits. ${ }^{57}$ The increased levels of CXCL- 8 in the host response against $\mathrm{TB}$ infection may be considered as an immune response. ${ }^{58}$ However, the precise role of CXCL-8 in TB infection remains unclear and merits further study specially with considering more control group as non TB smoker.

In conclusion, the results of this study revealed that smoking could play role in imbalance of immune system in TB patients which may indicate by differences in phagocytosis and expression of proinflammatory mediators. Importantly, both phagocytosis impairment and CXCL-8 levels elevation were modified in TB smokers and it was correlated with smoking exposure. This highlights the important interactions of cigarette smoking and evasion of immune surveillance in TB patients. We speculate that serum TNF- $\alpha$, CXCL- 8 and phagocytosis may considered as useful biomarkers for anticipating smoker's immunologic response in TB patients.

\section{ACKNOWLEDGEMENTS}

The authors would like to appreciate the National Research Institute of Tuberculosis and Lung Diseases (NRITLD) and Shahid Beheshti University of Medical Sciences who granted this project.

\section{REFERENCES}

1. Hassmiller KM. The association between smoking and tuberculosis. Salud Publica Mex 2006, 48(suppl 1):S20116. 
2. World Health Organization. Global tuberculosis control: WHO report 2010. World Health Organization, 2010.

3. Crevel R v, Ottenhoff THM, van der Meer JWM. Innate Immunity to Mycobacterium tuberculosis. Clin Microbiol Rev 2002 Apr; 15(2):294-309.

4. Mortaz E, Adcock I M, Tabarsi P, Masjedi M R, Mansouri D, Velayati A A, et al. Interaction of Pattern Recognition Receptors with Mycobacterium Tuberculosis. J Clin Immunol 2014; 35:1-10.

5. Mortaz E, Varahram M, Farnia P, Bahadori M, Masjedi MR. New Aspects in Immunopathology of Mycobacterium tuberculosis. ISRN Immunology. 2012.

6. Davies P, Yew W, Ganguly D, Davidow A, Reichman L, Dheda K, et al. Smoking and tuberculosis: the epidemiological association and immunopathogenesis. Trans R Soc Trop Med Hyg 2006; 100(4):291-8.

7. Elssner A, carter JE, Yunger TM, Wewers MD. HIV-1 infection does not impair human alveolar macrophage phagocytic function unless combined with cigarette smoking. Chest 2004; 125(3):1071-6.

8. Oddo M, Renno T, Attinger A, Bakker T, MacDonald HR ,Meylan PR. Fas Ligand-Induced Apoptosis of Infected Human Macrophages Reduces the Viability of Intracellular Mycobacterium tuberculosis. J Immunol 1998; 160(11):5448-54.

9. Keane J, Balcewicz-Sablinska MK, Remold HG, Chupp GL, Meek BB, Fenton MJ, et al. Infection by Mycobacterium tuberculosis promotes human alveolar macrophage apoptosis. Infect Immun 1997; 65(1):298304.

10. Kirkham PA, Spooner G, Ffoulkes-Jones C, Calvez R. Cigarette smoke triggers macrophage adhesion and activation of lipid peroxidation products and scavenger receptor. Free Radic Biol Med 2003; 35(7):697-710.

11. Nouri-Shirazi M, Guinet E. Evidence for the immunosuppressive role of nicotine on human dendritic cell functions. Immunology $2003 \mathrm{Jul}$; 109(3):365-37.

12. Pankow W, Neumann K, Rüschoff J, Schröder R, von Wichert P. Reduction in HLA-DR antigen density on alveolar macrophages. Lung 1991; 169(5):255-62.

13. Sköld CM, Lundahl J, Halldén G, Hallgren M, Eklund A. Chronic smoke exposure alters the phenotype pattern and the metabolic response in human alveolar macrophages. Clin Exp Immunol 1996; 106(1):108-13.

14. Parihar A, Eubank TD, Doseff AI. Monocytes and macrophages regulate immunity through dynamic networks of survival and cell death. J Innate Immun 2010; 2(3):204-15.

15. Scott Algood HM, Ling Lin P, Flynn JL. Tumor Necrosis
Factor and Chemokine Interactions in the Formation and Maintenance of Granulomas in Tuberculosis. Clin Infect Dis 2005; 41:(Suppl 3):S189-93.

16. Parameswaran N, Patial S. Tumor necrosis factor-alpha signaling in macrophages .Crit Rev Eukaryot Gene Expr 2010; 20(2):87-103.

17. Keane J, Gershon S, Wise RP, Mirabile-Levens E, Kasznica J, Schwieterman WD, et al. Tuberculosis associated with in- fliximab, a tumor necrosis factor aneutralizing agent. N Engl J Med 2001; 345(15):1098104.

18. Keane J. Tumor necrosis factor blockers and reactivation of latent tuberculosis. Clin Infect Dis 2004; 39(3):300-2.

19. Miranda M S, Breiman A, Allain S, Deknuydt F, Altare F. The tuberculous granuloma: an unsuccessful host defence mechanism providing a safety shelter for the bacteria? Clin Dev Immunol 2012; 2012:139127.

20. Ameixa C, Friedland JS. Interleukin-8 secretion from Mycobacterium tuberculosis-infected monocytes is regulated by protein tyrosine kinases but not by ERK1/2 or p38 mitogen-activated protein kinases. Infect Immun 2002; 70(8):4743-6.

21. Lin Y, Zhang M, Barnes PF. Chemokine production by a human alveolar epithelial cell line in response to Mycobacterium tuberculosis. Infect Immun 1998; 66(3):1121-6.

22. Wickremasinghe M I, Thomas L H , Friedland JS. Pulmonary epithelial cells are a source of IL-8 in the response to Mycobacterium tuberculosis: essential role of IL-1 from infected monocytes in a NF- $\kappa$ B-dependent network. J Immunol 1999; 163(7):3936-47.

23. KrupaA, Fol M, Dziadek BR, Kepka E, Wojciechowska $\mathrm{D}$, Brzostek A, et al. Binding of CXCL8/IL-8 to Mycobacterium tuberculosis Modulates the Innate Immune Response. Mediators Inflamm 2015; 2015:124762.

24. Sopori M. Effects of cigarette smoke on the immune system. Nat Rev Immunol 2002; 2(5):372-7.

25. Matsunaga K, Klein TW, Friedman H,Yamamoto Y. Involvement of nicotinic acetylcholine receptors in suppression of antimicrobial activity and cytokine responses of alveolar macrophages to Legionella pneumophila infection by nicotine. J Immunol 2001; 167(11):6518-24.

26. Aoshiba K, Tamaoki J, Nagai A. Acute cigarette smoke exposure induces apoptosis of alveolar macrophages. Am J Physiol Lung Cell Mol Physiol 2001;281(6):L1392-401.

27. Talhout R, Schulz T, Florek E, van Benthem J, Wester P, Opperhuizen A. Hazardous Compounds in Tobacco 


\section{Attenuation Release of TNF and CXCL-8 in TB and Smoking}

Smoke. Int J Environ Res Public Health 2011; 8(2):61328.

28. Rodgman A, Perfetti TA. The chemical components of tobacco and tobacco smoke. CRC press; 2013.

29. Fowles J, Bates M, Noiton D. The chemical constituents in cigarettes and cigarette smoke: priorities for harm reduction. Porirua, New Zealand: Epidemiology and Toxicology Group, Institute of Environmental Science and Research Ltd. 2000.

30. Church DF, Pryor WA. Free-radical chemistry of cigarette smoke and its toxicological implications. Environ Health Perspect 1985; 64:111-126.

31. Bothamley G. Smoking and tuberculosis: a chance or causal association? Thorax 2005; 60(7):527-8.

32. Van der Vaart H, Postma D, Timens W, Ten H. Acute effects of cigarette smoke on inflammation and oxidative stress: a review. Thorax 2004; 59(8):713-21.

33. Hodge S, Hodge G, Ahern J, Jersmann H, Holmes M, Reynolds PN. Smoking alters alveolar macrophage recognition and phagocytic ability: implications in chronic obstructive pulmonary disease. Am J Respir Cell Mol Biol 2007; 37(6):748-55.

34. World Health Organization. Treatment of tuberculosis: guidelines. World Health Organization; 2010.

35. Mortaz E, Gudarzi H, Tabarsi P, Adcock I M, Masjedi MR, Jamaati HR, et al. Flow Cytometry Applications in the Study of Immunological Lung Disorders. Iran J Allergy Asthma Immunol

2015; 14(1):12-18.

36. Yuan F, Fu X, Shi H, Chen G, Dong P, Zhang W. Induction of Murine Macrophage M2 Polarization by Cigarette Smoke Extract via the JAK2/STAT3 Pathway. PLoS One 2014; 9(9):e107063.

37. Van Amersfoort ES, Van Strijp JA. Evaluation Of a Flow Cytometric Fluorescence Quenching Assay Of Phagocytosis Of Sensitized Sheep Erythrocytes By Polymorphonuclear Leukocytes .Cytometry 1994; 17:(4):294-301

38. Hashemian SMR, Mortaz E, Tabarsi P, Jamaati H, Maghsoomi Z, Khosravi A et al. Elevated CXCL-8 expression in bronchoalveolar lavage correlates with disease severity in patients with acute respiratory distress syndrome resulting from tuberculosis. J Inflamm (Lond) 2014;11:21.

39. Lozano R, Laghavi M, Foreman K, Lim S, Shibuya K, Aboyans V, et al. Global and regional mortality from 235 causes of death for 20 age groups in 1990 and 2010: a systematic analysis for the Global Burden of Disease Study 2010. Lancet 2012; 380(9859):2095-128.
40. World Health Organization. Health statistics and information systems: estimates for 2000-2012: causespecific mortality. Geneva: WHO; c 2015.

41. Patra J, Jha P, Rehm J, Suraweera W. Tobacco smoking, alcohol drinking, diabetes, low body mass index and the risk of self-reported symptoms of active tuberculosis: individual participant data (IPD) meta-analyses of 72,684 individuals in 14 high tuberculosis burden countries. PLoS One 2014; 9(5):e96433.

42. Lin HH, Ezzati M, Murray M. Tobacco smoke, indoor air pollution and tuberculosis: a systematic review and metaanalysis. PLoS Med 2007; 4(1):e20 .

43. Shang S, Ordway O, Henao-Tamayo M, Bai X, Oberley-Deegan R, Shanley C, et al. Cigarette smoke increases susceptibility to tuberculosis-evidence from in vivo and in vitro models. J Infect Dis 2011; 203(9):1240 8.

44. Karavitis J, Kovacs EJ. Macrophage phagocytosis: effects of environmental pollutants, alcohol, cigarette smoke, and other external factors. J Leukoc Biol 2011; 90(6):106578.

45. Harris J O, Swenson EW, Johnson J. Human alveolar macrophages: comparison of phagocytic ability, glucose utilization, and ultrastructure in smokers and nonsmokers. J Clin Invest 1970; 49(11):2086-96.

46. Fullerton DG, Jere K, Jambo K, Kulkarni NS, Zijlstra EE, Grigg J, et al. Domestic smoke exposure is associated with alveolar macrophage particulate load. Trop Med Int Health 2009; 14(3):349-54.

47. Ortega E, Barriga C, Rodriguez AB. Decline in the phagocytic function of alveolar macrophages from mice exposed to cigarette smoke. Comp Immunol Microbiol Infect Dis 1994; 17(1):77-84.

48. Lundborg M, lohard U, Johansson A, Eklund A, Falk R, Kreyling W, et al. Phagolysosomal morphology and dissolution of cobalt oxide particles by human and rabbit alveolar macrophages. Exp Lung Res 1995; 21(1):51- 66

49. Zoppini G, Faccini G, Muggeo M, Zenari L, Falezza G, Targher G. Elevated plasma levels of soluble receptors of TNF-a and their asso- ciation with smoking and microvascular complications in young adults with type 1 diabetes. J Clin Endocrinol Metab 2001; 86(8):3805-8.

50. Fernandez-Real J-M, Broch M, Vendrell J, Ricart W. Smoking, fat mass and activation of the tumor necrosis factor-a pathway. Int J Obes Relat Metab Disord 2003; 27(12):1552-6.

51. Khair OA, Devalia JL, Abdelaziz MM, Sapsford RJ, 


\section{Aryanpour, et al.}

Tarraf H, Davies RJ. Effect of Haemophilus influenzae endotoxin on the synthesis of IL-6, IL-8, TNF-alpha and expression of ICAM-1 in cultured human bronchial epithelial cells. Eur Respir J 1994; 7(12):2109-16.

52. Wilson M, Seymour R, Henderson B. Bacterial perturbation of cytokine networks. Infect Immun 1998; 66(6):2401-9.

53. Mueller-Ortiz SL, Wanger AR, Norris SJ. Mycobacterial protein HbhA binds human complement component C3. Infect Immun 2001; 69(12):7501-11.

54. van Zyl-Smit RN, Binder A, Meldau R, Semple PL, Evans A, Smith P, et al. Cigarette smoke impairs cytokine responses and BCG containment in alveolar macrophages. Thorax 2014; 69(4):363-70.

55. Thillai M, Eberhardt C, Lewin AM, Potiphar L, HingleyWilson S, Sridhar S, et al. Sarcoidosis and tuberculosis cytokine profiles: indistinguishable in bronchoalveolar lavage but different in blood. PLoS One 2012; 7(7):e38083.

56. Martin TR, Goodman RB. Chemokines in acute lung injury. Lung Biology in Health and Disease. 2003; 172:189-220

57. Krupa A, Fol M, Dziadek B R, Kepka E, Wojciechowska D, Brzostek A, et al. ArticleBinding of CXCL8/IL-8 to Mycobacterium tuberculosis Modulates the Innate Immune Response. Mediators Inflamm 2015; 2015:124762.

58. Lyons MJ, Yoshimura T, McMurray DN. Interleukin (IL)-8 (CXCL8) induces cytokine expression and superoxide formation by guinea pig neutrophils infected with Mycobacterium tuberculosis .Tuberculosis (Edinb) 2004; 84(5):283-92. 